\title{
A Sociolinguistic Study of Deviant Orthographic Representation of Graduating Students' Names in a Nigerian University
}

\author{
Oladunjoye J. Faleye/Adeyemi Adegoju (Ile-Ife, Nigeria)
}

\begin{abstract}
It is habitual for graduating students of the Obafemi Awolowo University, Ile-Ife, Nigeria, to roll out the drums the very day they finish writing their final examination. Characteristic of such a ritualistic exercise, among other things, are the brand names the students coin for themselves from their original names. This study focuses on the creative rewriting of the names on such an occasion and examines the linguistic habits exhibited therein. It analyses the phonological/graphematic features that mark the rewritng of the names and discusses the sociolinguistic implications for the phenomena of social identity construction and language contact situation. Data for the study was sourced mainly through participant-observation technique with a supplemment of an oral interview conducted for some of the subjects between year 2007 and 2009. The data was selected through a purposive random sampling technique which yielded fifty names that were considered representative of the respelling conventions. The paper employs mainly Hempenstall's (2003) Phonological Sensitivity Skills to analyse the linguistic practices in the reconfigured names and then applies Tajfel's and Turner's (1979) Social Identity Theory to explain how it is that people develop a sense of membership and belonging in particular groups. The article reveals that the deviant orthographic conventions are a major fallout of youth culture with great influence from computer-mediated communication. It also shows that their linguistic experimentation foray in the discourse greatly undermines the orthographic system of the indigenous language (Yoruba) and the cultural values embedded in the original names.
\end{abstract}

\section{Introduction}

No matter the cross-cultural variations that characterise human societies the world over, one phenomenon that is constant is the identity constructed for an individual via the name(s) they bear. Names are a valuable source of information which can indicate gender, birthplace, nationality, ethnicity, religion and position within a family and even in the larger society. According to Mphande (2006: 106), "[n]ames [...] are the most meaningful lexicon in the vocabulary of any language, and they are an important part of the language inventory [...]". Names are, therefore, that social emblem crafted for and attached to every human no matter their creed, sex, ethnic affiliation or nationality. But ubiquitous as the phenomenon is, every culture has its own naming practices and the implications of such names for the construction of identity for individuals.

Therefore, naming practices vary considerably across the globe. For instance, a Nigerian, say of Yoruba extraction, would wonder why an English man would bear such names as Stone, Wood, Rice, Fox, Grass, Green and the likes, as such names do not seem to make any meaning to the outsider in terms of their underlying cultural essence. This is because among the Yoruba, names are given to reflect circumstantial factors relating to the birth of a child apart from having bearings with the lineage, religion, culture, vocation and values of the people. For instance, some names such as Asake and Asabi (for female) and Alani and Isola (for 
male $)^{1}$ are based on panegyric attributes; some have to do with congenital circumstances such as Taiwo and Kehinde (twins and unisex) ${ }^{2}$, Ojo (for male), Aina (for female) ${ }^{3}$, Ajayi and Ige (unisex) ${ }^{4}$; and some names touch on the people's belief in reincarnation, as children born after the demise of a grandfather or a grandmother could be named Babatunde (for male) and Iyabode (for female) $)^{5}$.

The fact is established in the literature that there is an intrinsic connection between naming and identity construction. De Pina-Cabral (2008: 5) argues that "naming processes carry with them implications concerning what a person is and how he or she is placed in the world [...]". Thus, the question of identity is almost always tied to naming practices. Norton (2000: 5) views identity as how a person understands his/her "relationship to the world, how this relationship is constructed in time and space, and how the person understands possibilities for the future". Park (2007: 341) cited in Barnawi (2009: 65) sees identity as "an inherently social product that is jointly created by interactants, rather than as a pre-determined, psychological construct that is lodged within each individual's mind". Reicher (2004: $928 \mathrm{f}$.) argues: "[...] we clearly belong to a variety of social groups that are differentially salient to us in different conditions $[\ldots]$. It is the shift from personal to social identity that underlies the behavioural shift from interpersonal to intergroup behaviour."

According to Val and Vinogradova (2010: 1), researchers have pointed out that identity is dynamic and socially constructed. They have also noted that identity is negotiated in discourse and thus influenced by language, which creates the medium for its negotiation. Ansaldo (2010: 615) sees the alignment between language and identity as "complex" and "continually shifting". Barnawi (2009: 66) opines that "language acts as a mediating tool for constructing and deconstructing individual and social identities". Therefore, the present study focuses on linguistic practices of youths, as the question of youth, language and identity has become an interesting research focus in variationist studies. Pujolar (2008: 1) posits:

[...] there is a certain sociological common sense that sees youths as the seed of future society and, therefore, as the segment where we can best evaluate the progress of various political projects: recuperation of the use of language, equality of the sexes, presence or absence of prejudice of all kinds, attitudes to nature, cultural differences, etc.

In the light of the foregoing, the present researchers are struck by a social event in which the inner workings of language are explored in a particularly novel and ingenious way by the graduating students of the Obafemi Awolowo University, Nigeria, who are mostly youths. On the day they finish writing their final examination, they wear customised T-shirts with their reconfigured names boldly embossed at the back of the shirts, dance to tuneful melodies and burst into wild ecstasy, having purportedly survived the challenges of the system. While the ordinary observer would be carried away by their dancing steps and the choice of religious/victory songs packaged for the occasion, the present researchers are interested in

\footnotetext{
1 There are many Yoruba names in this category that people traditionally give their children as praise names. Such names are from time to time used to spur the bearers at moments of great expectations or in times of challenges.

2 Twins, among the Yoruba, are considered rare gifts from God. As such, they are highly prized such that they are even celebrated traditionally with some special ceremonies periodically when food items are shared with loved ones. Taiwo is the first child at birth, while Kehinde is the second.

${ }^{3}$ Ojo and Aina are names given to children that have the placenta woven round their necks at birth. The former is given to the male child, while the latter is given to the female.

${ }^{4}$ Ajayi is the name of a child, either male or female, that turns his/her face downwards at birth. Ige is the child that comes out of the womb with the legs instead of the head. Such a child is usually treasured because of the threat constituted to the mother's life and that of the child himself/herself.

5 The Yoruba believe in reincarnation. So, when a child is born shortly after a grandmother or grandfather dies, the child (a male) is named Babatunde - Grandpa has come again - and if the child is female, she is given the name Iyabode - Grandma has come again.
} 
investigating the phonological/graphematic aspect of the renaming process and the sociolinguistic motivations for such an exercise in sheer linguistic audacity. The study is interested in describing not only the linguistic practices in the discourse but also in accounting for the prevailing social milieu in which they are exhibited. It analyses the particular instances of the deviant orthographic patterns evidenced in the rewriting of the students' names and the rite of passage which the students seem to engage in at a momentous occasion of their academic odyssey. Thus, the study considers the linguistic patterns of the rewriting trend as not being exclusively phonetic patterns but sociolinguistic patterns as well.

\section{Methodology}

The data for this study was drawn from the rewritten names displayed on the customised Tshirts of three sets of graduating students of the university from 2007 to 2009. The names were generally studied to acquaint the researchers with the linguistic style inherent in them. Having observed the naming practices in the corpus and the attendant linguistic means of realising them, the researchers then purposively sampled one hundred and fifty names for the three different years that the study covers (fifty names per year). After a careful study of the names in terms of coinages and structures, the researchers observed considerable overlap in the orthographic conventions deployed by the subjects and then settled for fifty of such names that were representative of the rewriting conventions that characterise the corpus generally.

Principally, the data for the study was collected through the participant-observation method which created the avenue for the researchers to fully document the names in the corpus collected for the study. However, the researchers had to conduct an oral interview with about half of the subject population. The researchers approached the subjects as admirers and people who shared their joy and in the process sought to enquire why they reconfigured their names and how they came about the spelling. Besides, the interview became necessary because some of the reconfigured names appeared so esoteric in orthography that it would require the bearers to provide some clues as to how such names could be decoded.

In terms of the age brackets of the subjects, investigation revealed that their ages ranged between twenty and twenty-seven, validating the fact that they were youths. In fact, some females mainly that fell within this age bracket but were already married abstained from the social practice probably because they considered the fact that they had outgrown such a youth spree. Besides, adherents of Christianity and Islam with strong doctrinal inclinations also abstained from the social practice, thereby suggesting that there is also a religious identity perspective to the social practice. Generally, elderly graduating students in their thirties and forties were not part of the social engagement.

\subsection{Theoretical Considerations}

In order to account for the structural features of the discourse, the paper employs Hempenstall's (2003) Phonological Sensitivity Skills in explaining the orthographic conventions observed in the data. The study, however, applies only four of Hempenstall's (2003) twelve stages of phonological sensitivity because the others did not occur in the data rather than as a choice by the authors of the study. Stanovich (1986: 362) succinctly defines phonological sensitivity skills as the 'conscious access to the phonemic level of the speech stream and some ability to cognitively manipulate representations of this level'.

The study equally draws insights from Arab-Moghaddam's and Senechal's (2001) view that different languages employ diverse phonological skills in designing their orthographic complexities. Koffi (2006) corroborates their view by identifying two broad categories of spellings: the deep or opaque and the shallow or transparent orthographies. An opaque orthography is a model in which there is no one-to-one correspondence between letters and sounds. 
Languages that employ this type of spelling strategy are termed polyphonic languages. English and French languages employ this type of orthography. Transparent orthography is based on sound-to-letter correspondence principle. In this type of orthography, a letter consistently represents the same sound and a phoneme is consistently represented by the same letter. Examples are found in some Nigerian languages like Yoruba. Hence, this study attempts to examine how the subjects manipulate the two models of orthography in the reconfiguration of their names.

To account for the ideological underpinning of the subjects' linguistic practices, the paper applies Social Identity Theory as developed by Tajfel and Turner (1979). In the Social Identity Theory, a person has not one, 'personal self', but rather several selves that correspond to widening circles of group membership. Therefore, apart from the 'level of self', an individual has multiple 'social identities'. One interesting thing to note is that people can be part of multiple groups, and that the part of their identity which is most dominant can change, depending on which group they are associating with. In other words, it is an individual-based perception of what defines the 'us' associated with any internalised group membership. This can be distinguished from the notion of personal identity which refers to self-knowledge that derives from the individual's unique attributes. Through social identity, the subject is defined in social terms.

One of the concepts behind Social Identity Theory is categorisation, that is, the idea that humans all categorise one another, creating a set of natural groups. Social Identity Theory asserts that group membership creates in-group/self-categorisation and enhancement in ways that favour the in-group at the expense of the out-group. After being categorised as members of a group, individuals seek to achieve positive self-esteem by positively differentiating their in-group from a comparison out-group on some valued dimension. This quest for positive distinctiveness means that people's sense of who they are is defined in terms of "we" rather than "I". Against this background, this study attempts to locate the linguistic practices of reconfiguring names among our subjects within the purview of social identity construction.

\section{$3 \quad$ Analysis of Data}

The subjects employ the phonological sensitivity strategy that words can begin with the same sound. A number of the names on the subjects' T-shirts start with similar initial sounds. The initial sounds are formed by using specific letters to replace some of the ones in the mother tongue, that is, Yoruba. For example, $b h$ is used instead of $b$ in names like Bhollar with tonal pattern of (HH) and Bhayor (HL) for Bola and Bayo respectively. $P h$ is also used instead of $f$ in Phemmy (HM) and Phollar (MH) for Femi and Fola respectively. The similarities in the initial spelling of the names are shown in Table 1 below:

\begin{tabular}{|c|c|c|c|c|}
\hline Letter & Phoneme/Grapheme & New Letters & $\begin{array}{l}\text { Reconfigured } \\
\text { Names in Social } \\
\text { Context }\end{array}$ & $\begin{array}{l}\text { Original Ver- } \\
\text { sions in L1 }\end{array}$ \\
\hline $\mathrm{B}$ & $/ \mathrm{b} /$ & $\mathrm{Bh}$ & Bholar & Bola \\
\hline $\mathrm{F}$ & $/ \mathrm{f} /$ & $\mathrm{Ph}$ & Phemmy, Phorlar & Fola \\
\hline $\mathrm{R}$ & $/ \mathrm{r} /$ & $\mathrm{Rh}$ & $\begin{array}{l}\text { Rhemmy, } \\
\text { Rhorlarche, } \\
\text { Rhonche }\end{array}$ & $\begin{array}{l}\text { Remi, } \\
\text { Ronke }\end{array}$ \\
\hline $\mathrm{Y}$ & $/ \mathrm{j} /$ & $\mathrm{Yh}$ & Yhemmy & Yemi \\
\hline $\mathrm{K}$ & $/ \mathrm{k} /$ & $\mathrm{Ch}$ & Chemmy, Khikhe & Kemi, Kike \\
\hline $\mathrm{O}$ & $/ 0 /$ & Orh, Hur, Or & $\begin{array}{l}\text { Orhlarmmydey, } \\
\text { Hurmoretahyour, } \\
\text { Orchor }\end{array}$ & $\begin{array}{l}\text { Olamide, } \\
\text { Omotayo, Osho }\end{array}$ \\
\hline $\mathrm{O}$ & $\mathrm{O}$ & Ho & $\begin{array}{l}\text { Houykunterdey, } \\
\text { Houykhecholar }\end{array}$ & $\begin{array}{l}\text { Okuntade, } \\
\text { Okesola }\end{array}$ \\
\hline A & $\mathrm{a}$ & Hay/ha/her & $\begin{array}{l}\text { Harbbeykey, } \\
\text { Hadehbholar, }\end{array}$ & $\begin{array}{l}\text { Abike, Adebola, } \\
\text { Akinola }\end{array}$ \\
\hline
\end{tabular}




\begin{tabular}{|l|l|l|l|l|}
\hline & & & Herkintorlar & \\
\hline E & e & Ehy/Eh & Ehytorpeh & Eyitope \\
\hline
\end{tabular}

Table 1: Names Beginning with the Same Sound

In most of the items, letter $h$ is placed after the initial letters of $b, p, y$ and $k$ to produce the following digraphs $b h, p h, r h$, and $k h$ as shown in Table 1 above. Similarly, the letter $h$ comes after letters o, $a$, and $e$ to form $o h, a h$ and $e h$ or before some letters: $o$ represented as /ou/ in Houykunterdey (LHMM) and Hauykeychorlar (LHMH) for Okuntade and Okesola respectively and [a] in names like Hadehbholar (MHHH) and Herkintorlar (MHHH) for Adebola and Akinola in that order. The effect of all these is the creation of extra digraphs in the resultant orthography which are alien to Yoruba orthography which hitherto has only one digraph $g b$ through the addition of $h$ to some letters in the pre- or post-consonantal and vocalic positions.

The subjects also make use of their knowledge of the phonological sensitivity skill that words can end with same sound in the orthographic representations of their names. There is the addition of $h, r$ and $y$ at the post vocalic word final positions in the spellings. This style of orthography leads to the coinage of spellings like Larrah (MH), Bhollar (HH), and Bayour (HL) for Lara, Bola and Bayo respectively. In the same vein, we have Orlarmmydeh (MHHH) and Bhayourdey (HLH) for Olamide and Bayode respectively. Finally, letter y replaces the Yoruba letter $i$ in words like Phemmy (HM), Chemmy (HM) and Yhemmy ([MH) for Femi, Kemi and Yemi respectively. The pattern is shown in Table 2 below:

\begin{tabular}{|l|l|l|l|l|}
\hline $\begin{array}{l}\text { Ending } \\
\text { Letter in L1 }\end{array}$ & Phoneme/Grapheme & $\begin{array}{l}\text { Innovative } \\
\text { Letters }\end{array}$ & $\begin{array}{l}\text { Reconfigured } \\
\text { Names in Social } \\
\text { Context }\end{array}$ & $\begin{array}{l}\text { Original } \\
\text { Versions in } \\
\text { L1 }\end{array}$ \\
\hline $\mathrm{a}$ & $\mathrm{a}$ & ah/ar & $\begin{array}{l}\text { Larrah, Bhollar } \\
\text { Herkintolar }\end{array}$ & $\begin{array}{l}\text { Lara, Bola, } \\
\text { Akintola }\end{array}$ \\
\hline $\mathrm{e}$ & $\mathrm{e}$ & $\mathrm{ey}$ & Orhlarmmydey & Olamide \\
\hline $\mathrm{i}$ & $\mathrm{i}$ & $\mathrm{y}$ & $\begin{array}{l}\text { Rhemmy, } \\
\text { Phemmy, } \\
\text { Yhemmy, } \\
\text { Chemmy }\end{array}$ & $\begin{array}{l}\text { Remi, Femi, } \\
\text { Yemi, Kemi }\end{array}$ \\
\hline $\mathrm{o}$ & $/ \mathrm{s} / \mathrm{Dayour,}$ & $\begin{array}{l}\text { Dayo, Bayo } \\
\text { Bhayour }\end{array}$ \\
\hline
\end{tabular}

Table 2: Word Ending with Same Sound

From Table 2, it could be observed that vocalic segments [a], [e], [i] and /o/ are orthographically represented as ah/ar for [a], ey for [e], $y$ for [i] and or/our for $/ \mathrm{s}$.

They also utilise the skill that letters can be blended to form certain sounds, as there are some digraphs used in place of single letters in the original names. These digraphs contain various letters which are blended to form certain sounds. For example, the three letters in our are blended to realise the $/ \mathrm{J} /, p h$ is blended to form $/ \mathrm{f} /$ and $y h$ is realised as $/ \mathrm{j} /$ in words like Bhayour, Phemmy and Yhemmy respectively. Interestingly, some of the subjects employ broad transcription in writing their names instead of using the conventional orthographic form. Examples are found in /derdoujn/ instead Dedoyin (HMM) and /lardei/ instead of Laide (HHH). In some cases, the subjects make use of the pronunciation of each of the letters making up spellings of their names. For example, Lola is written as El-OH-EL-AHE, where each of the 
segments hyphenated represents the pronunciation of the English letters in the name Lola. This type of orthographic style would create some obscurantism for the reader. Unless one belongs to the circle of users, it becomes difficult decoding such names. As revealed from the interview, some of the bearers of such names that have a good knowledge of transcription actually transcribed the names themselves while those that are deficient in it but fancy the style had to commission their friends to carve that distinct identity for them.

Finally, the subjects transfer their knowledge of homophonic (sameness of sounds) and homographic (sameness of sounds and spellings but different meanings) words in English to the rewriting of their names. They deliberately employ words/sounds that have sameness of sound with any aspect of their names in configuring their names. For example, the subjects use saw which is realised as /so:/ as a substitute for so in the medial syllable of Busola, thereby resulting in the writing of Bhusawlar for Busola [LHH]. Similarly, Beesee, a compound word consisting of bee and see, is used to replace Bisi $[\mathrm{HH}]$. It appears that all that the students are after seems to be hinged on playing on the similarities of the sounds. But they seem to pay little or no attention to the differences in the vowel duration of unrounded close front vowels in the different nodes of Beesee /br:si:/ as opposed to unrounded half close front vowels in 'Bisi' [bisi] with tonal pattern $[\mathrm{HH}]$. The deliberate use of saw, bee and see in writing Yoruba names represent a fusion of English orthography with that of Yoruba, thereby creating a point of convergence between opaque and transparent orthographies. It has also brought about the infusion of long vowels which are absent in the Yoruba language into the pronunciation of names in the language.

At another level, there is also the injection of mathematical symbols into the writing of names, thereby merging letters and figures in the written names. Examples are found in names like $X n$ for Teni $[\mathrm{HH}]$, 4lar for Fola $[\mathrm{MH}]$. A closer look at these names reveals much about the background of the users of this writing system, particularly in writing text messages or chatting on Facebook. In $X n$, the $X$ is the Roman symbol for the number that in English is called 'ten'. The addition of letter $n$ to $X$ corresponds to an $i$-epenthetic vowel in the orthographic representation of Teni. In the same vein, in 4lar, the subjects played on the sound of /fo:/ in 4 and blends it with lar [1a] to form 4lar instead of Fola [MH].

The spellings in the data show a heavy dose of opaque orthographic representation of Yoruba names, thereby coming up with different words that feature silent letters. Silent letters are graphemes that are elided during the process of articulation of an utterance. For example, in words like Hardebholah, Hoyehkhemmy and Kheakhe, the grapheme $h$ in the names is added to defamiliarise the familiar names through the distortions in the spellings of Adebola $[\mathrm{MHHH}]$, Oyekemi $[\mathrm{MLHM}]$ and Kike $[\mathrm{HH}]$ respectively but is elided in their pronunciations. As some of the subjects responded to the oral interviews, such a convention is born out of sheer exercise in linguistic experimentation.

\subsection{Implications of the Naming Practices for Identity Construction}

According to Cerulo (1997: 386), quoting Appiah and Gates (1995: 1), identity studies have been relocated to the site of the collective, with gender/sexuality, race/ethnicity, and class forming the "holy trinity" of the discursive field. Therefore, at the level of the collective, scholars are examining the mechanics by which distinctions are created, maintained, and changed. This development validates the view that one could have multiple identity positions and then move among these in different social contexts, thereby portraying identity as a "process of association and opposition" (Achugar 2006: 100) and of constant negotiation, production and performance (Crawshaw et al. 2001) rather than a static category of possession. 
It is instructive that the original names (with the usual spelling conventions) which these graduating students bear not only at home but also officially in their school records and their existing certificate(s) have not been discarded at all. It is the social force of attaining a particular feat at a transitional phase in life that has conditioned them to associate with the collective, a graduating set, say "class of 2007", "class of 2008", or "class of 2009", whose experiences and memories they would live to relish. In such a case, the class seeks a collective identity not only in terms of group photographs or a special outfit but also in reconstruction of identity for the collective. Androtsopoulos and Georgakopoulou (2003: 1) opine:

It is by now a truism within discourse studies that identities are neither fixed nor categorical properties residing in people's minds; instead, they are emergent in the sequentiality of discourse, particularly in interactional sites, where they are dynamically (re)created [...]. In this way, their constructions in any speech event are marked by indeterminacy and irreducible situational contingency: e.g. certain identity aspects may be made more salient or relevant than others at different points of an interaction; in similar vein, identities can be actively reconstructed, reframed, and, even more or less consciously, transgressed and reconstituted [...] by discourse participants to suit local interactional projects.

The social practice of reconfiguring names to mark the collective seems to resonate with a popular event in the marketing world where a product is branded for legitimacy and acceptability. As graduating students, they appear to cut the figure of professionals who at the point of being unveiled to the public at a turning point in their career savour the new world they are stepping into not necessarily by reconfiguring their names but by adding them to the desirable image of the establishment or the organisation they are joining. By rewriting their names and thereby acquiring new names, as it were, the graduating students seem to be announcing their new status, new image and the need to mark such a rite of passage with the reconstruction of their identity. This is nothing short of a rebranding effort which is common in the advertising or marketing world. Such a rewriting convention constructs a new identity for the bearers not just for the present time but also, as some of the subjects revealed during the interview session, a form of memorabilia to mark a transitional phase in their academic career.

\subsection{Implications of the Naming Practices for Contact Linguistics}

In order to help us to understand the results in the sociolinguistic context, we will first of all give a description of the general status of English in relation to other languages spoken in Nigeria. To this effect, it would interest us to note that Nigeria is commonly regarded as a country with extreme linguistic fragmentation. According to Oyetade (2003: 105), "the present linguistic situation in the country may be understood in the context of a worldwide process of balkanisation". Given this picture, Adegbija (2004: 181) submits: "Nigeria, the most multilingual country in Africa, has well over 450 languages". However, the number of languages in Nigeria with their respective speakers is indeterminable, as Adegbija (2004: 181) argues:

Because language issues in Nigeria are often quite explosive and conflict ridden, censuses never have items or questions on languages. Thus, reliable statistics relating to issues like number of languages, their spread, the number of speakers of each, or what percentage of the population they constitute are rarely available.

In terms of the size of the various ethno-linguistic groups in the country, Oyetade (2003) notes that it may be convenient to recognise three distinct groups which are the three major languages: Hausa, Yoruba and Igbo. These are followed by languages of local importance, which are equally useful in their respective states. Languages in this category include: Edo, Efik, Kanuri, Tiv, Urhobo, Fulfulde, Igala, Nupe, Ijo, Itsekiri, Ebira, Annang, Gwari etc. The last category commonly referred to as the class of minority languages is composed of languages that are very small and are only useful in their respective communities. Adegbija 
(2004) recognises Nigerian Pidgin English as another language with a notable presence in the Nigerian linguistic landscape. It coexists with English and the indigenous languages. Simpson and Oyetade (2007) argue that currently there is still no recognised standard form of NPE or fully accepted way of writing the language, but it is used in television, on the radio, and in certain forms of literature.

Gut (2004) further notes that of all the languages in Nigeria, it is only English that enjoys a geographical spread throughout the country, the reason being that English is regarded as the official language in Nigeria. Therefore, it is used in predominantly formal contexts such as government, education, business and commerce and as a lingua franca in social interaction. In this linguistic context, it is interesting to note that an average educated Nigerian is a bilingual who can speak his/her indigenous language $\left(\mathrm{L}_{1}\right)$ and English $\left(\mathrm{L}_{2}\right)$ with different degrees of competence.

Significantly, therefore, this study sheds light on a contact linguistic situation, particularly in a second language environment. Afolayan (1968) and Atoye (1980) have commented on the interference of the indigenous languages on the mastery of English in Nigeria. This phenomenon exists either as "proactive" or "retroactive" interference (Akindele and Adegbite 1992: 31). It is interesting that it is not only the knowledge of the first language that could interfere with the learning of the second language. Hence, at another level, the interference of English with indigenous languages, like Yoruba, has been commented upon in studies carried out by Ekundayo (1987), Fabumi and Salau (2005) and Ayodele (2008).

Ekundayo (1987: 5) calls a situation in which structural and lexical items of $\mathrm{L}_{2}$ are adopted and used in place of existing structural and lexical items in the $\mathrm{L}_{1}$ as "suppressive interference". Ekundayo (1987) identifies suppressive lexical borrowing from English as shown in the names of the months and days of the week which have suppressed those in indigenous names in Yoruba. Similarly, Ayodele (2008) identifies, among other things, the use of English alphabet as initials of people's names, the non-use of Yoruba numerals and the non-use of Yoruba versions of religious words and names.

In line with the analysis carried out in the present study, while we may not claim that the deviant orthographic patterns in the reconfigured names are wholly influenced by English spelling patterns, as some are born out of sheer linguistic experimentation, we may not be able to rule out some incontrovertible instances of the interference of English spelling patterns on the reconfigured Yoruba names. For instance, the use of double consonants: $r r$ as in Larrah, double $\mathrm{mm}$ as in Khemmy; substitution of similar sounds: $q$ in English for Yoruba $k$ as in Bouque instead of Buki; ph in English for Yoruba $f$ as in Phemmy instead of Femi; and ch for $k$ as in Chemmy instead of Kemi; introduction of the consonant $r$ after a vowel which is characteristic of English orthographic convention: or, ar as in Phesayor and 4lar respectively instead of Fisayo and Fola are clear demonstrations of English spelling conventions interfering with the orthography of Yoruba. This takes us to the question of another context in which suppressive interference of English in a second language context like Nigeria manifests. This study provides a fresh data where suppressive interference of English manifests in the anglicisation of some of the spellings of the names of a class of graduating students in a Nigerian university.

\section{Conclusion}

This study has attempted a sociolinguistic analysis of the rewriting of names among graduating students of the Obafemi Awolowo University. In so doing, some issues that bear upon language, identity and identity reconstruction have been brought to the fore. Apparently, there seems to be little or no emphasis placed on identity construction that is born out of any driven semantic import as manifested in their reconfigured names. This is because the devised or- 
thographies largely obscure the inherent meanings of their names. What they seem to have done is to maintain group exclusiveness and convey a sense of comradeship via linguistic marking. The names set them out as a distinct social class, youths in their early and midtwenties who apparently in ten or fifteen years' time would not want to write their names the way they do now, for whatever social reason(s). So, for how long the subjects would keep the names is a matter of the social eclipse that they experience as they journey through life. But the fact remains that while they may not keep the names as aliases, they are still to some extent kept and remembered by old school mates. In fact, the souvenir (T-shirt) on which the names are embossed are likely to be kept for long as a memorabilia.

Since the new names do not announce new behavioural/personality traits, it stands to reason that as youths with creative minds, they try to engage in an exercise of sheer linguistic experimentation that one could say is largely informed by the seminal culture they have been exposed to in the university environment. The esoteric spelling style employed by the subjects is a product of wit and ingenuity, exuberance of mental activity. The spelling pattern is, therefore, a form of counter-cultural style used against the existing norms of the indigenous language. The cultural import of the original names which resides in certain root/stem words has been completely supplanted by sheer phonoaesthetic drive evidenced in the unconventional spellings and the concomitant inhibition of pronunciation and resultant distortion of meaning. This is because there are certain elements forming the nucleus of meaning in Yoruba names generally. They include ade, ayo, ola, Oluwa, omo, ife, oba ${ }^{6}$ etc. But when such core elements are orthographically distorted, a lot of values embedded in them in the indigenous language are undermined.

One would not gloss over the possible effects of linguistic developments in computer-mediated discourse as found in cyber language evidenced in the codes used in Facebook interaction or Netlog or even short message service (SMS) text messaging that the subjects may have been recently exposed to. Therefore, the practice of tampering with the orthographic conventions of their indigenous language could be a fall-out of the experimentation that they have been doing with the English language (a target language) in computer-mediated communication which is now being transferred to an indigenous language.

On a final note, one question that we may need to answer again is the possibility of reproducing this finding in other universities. Without mincing words, students of particular universities have distinct ways of marking such a social event. While in some universities graduating students would be bathed in water (not heated nor containing any chemical substance) immediately they leave the examination hall, some would go solemn by engaging in praising and singing galore in some other universities. In some universities, non-graduating students may go barbaric by subjecting the graduating students to serious beating with all manner of objects that they may get hold of in the vicinity. Such a practice, though very uncultured, is meant to see or send the graduating students off, as they themselves must have done the same to their predecessors.

\section{References}

Achugar, Mariana (2006): "Writers on the Borderlands: Constructing a Bilingual Identity in Southwest Texas". Journal of Language, Identity, and Education 5/2: 97-122.

Adegbija, Efurosibina (2004): "Language Policy and Planning in Nigeria". Current Issues in Language Planning 5/3: 180-246.

Akindele, Femi/Adegbite, Wale (1992): The Sociology and Politics of English in Nigeria: An Introduction. Ile-Ife: Debiyi-Iwa.

\footnotetext{
${ }^{6}$ Ade means crown; ayo means joy; ola means wealth; Oluwa means Lord; ife means love; and oba means king.
} 
Afolayan, Adebisi (1968): The Linguistic Problems of Yoruba Learners and Users of English. Unpublished $\mathrm{PhD}$ Thesis, University of London.

Androutsopoulos, Jannis K./Georgakopoulou, Alexandra (2003): Discourse Constructions of Youth Identities. Amsterdam: John Benjamins.

Ansaldo, Umberto (2010): "Identity Alignment and Language Creation in Multilingual Communities". Language Sciences 32: 615-623.

Arab-Moghaddam, Narges/Senechal, Monique (2001): "Orthographic and Phonological Processing Skills in Reading and Spelling in Persian English Bilinguals". International Journal of Behavioural Development 25/1-6: 140-147.

Atoye, Ralph O. (1980): Sociolinguistics of Phonological Interference in Yoruba English. Unpublished PhD Thesis, University of Sheffield.

Ayodele, Babatunde O. (2008): "Suppressive Linguistic Interference, Lexical Borrowing and Some Salient Considerations". Papers in English and Linguistics 9: 21-30.

Barnawi, Osman Z. (2009): "The Construction of Identity in $\mathrm{L}_{2}$ Academic Classroom Community: A Small Scale Study of Two Saudi MA in TESOL Students at North American University". Journal of Language and Linguistic Studies 5/2: 62-84. http://www.jlls.org/Issues/Volume 5/No.2/ozbarnawi.pdf, accessed December 22, 2010.

Cerulo, Karen A. (1997): "Identity Construction: New issues, New Directions". Annual Review of Sociology 23: 385-409. http://userpage.fuberlin.de/ gerhards/lehrangebot_ss06/identitaet_cerulo_1997.pdf, accessed December 15, 2010 .

Crawshaw, Robert/Callen, Beth/Tusting, Karin (2001): "Attesting the Self: Narration and Identity Change during Periods of Residence Abroad". Language and Intercultural Communication 1/2: 101-119.

De Pinar-Cabral, Joao (2008): "What's in a Name: Personal Identity and Linguistic Identity in a Cosmopolitan World. Preliminary version of paper written for the symposium on "Multilingualism and Intercultural Dialogue in Globalisation"". New Delhi, December 2008: 1-7.

Ekundayo, Samuel A. (1987): "English in Suppressive Interference". Ife Studies in English Language 1/1\&2: 5-13.

Fabunmi, Felix A./Salau, Akeem S. (2005): "Is Yoruba an Endangered Language?". Nordic Journal of African Studies 4/3: 391-408.

Gut, Ulrike B. (2004): "Nigerian English: Phonology". In: Schneider, Edgar W. et al. (eds.) (2004): A Handbook of Varieties of English. Berlin, De Gruyter: 813-830.

Hempenstall, Kerry (2003): Phonemic Awareness: What Does it Mean? A 2003 Update. http://www.educationnews.org/articles/phonemic-awareness-what-does-it-mean-a2003-update-.html, accessed May 11, 2010.

Koffi, Ettien (2006): "Designing Optimal and Supradialectal Orthographies". West African Linguistics Society - WALS 25 July 31 to August 06, 2006. Cotonou, Republic of Benin. http://www.orthographyclearinghouse.org/Papers\%20for\%20website/Designing\%20Optim al\%20and\%20Supradialectal\%20Orthographies.pdf, accessed December 12, 2010.

Mphande, Lupenga (2006): "Naming and Linguistic Africanisms in African American Culture". In: Mugane, John/Hutchison, John P./Worman, Dee A. (eds.) (2006): Selected Proceedings of the 35th Annual Conference on African Linguistics. Somerville, MA: 104113. www.lingref.com/cpp/acal/35/paper1301, accessed December 12, 2010.

Norton, Bonny (2000): Identity and Language Learning: Gender, Ethnicity and Educational Change. Essex: Perason.

Oyetade, Oluwole S. (2003): "Language Planning in a Multi-ethnic State: The Majorityminority Dichotomy in Nigeria". Nordic Journal of African Studies 12/1: 105-117. 
Pujolar, Joan (2008): "Youth, Language and Identity". Revista de Sociolinguitica, Winter 2008: 1-11.

Reicher, Stephen (2004): "The Context of Social Identity: Domination, Resistance, and Change". Political Psychology 25/6: 921-945. http://www.jstor.org/stable/3792283, acessed January 19, 2011.

Simpson, Andrew/Oyetade, Akintunde B. (2008): "Nigeria: Ethnolinguistic Competition in the Giant of Africa". In: Simpson, Andrew (ed.): Language and National Identity in Africa. Oxford, Oxford University Press: 172-198.

Stanovich, Keith E. (1986): "Matthew Effects in Reading: Some Consequences of Individual Differences in the Acquisition of Literacy". Reading Research Quarterly XXI/4: 360-407. http://www.psychologytoday.com/files/u81/Stanovich_1986_pdf, accessed November 23, 2010 .

Tajfel, Henri/Turner, John (1979): "An integrative Theory of Intergroup Conflict". In: Austin, William G./Worchel, Stephen (eds.): The Social Psychology of Intergroup Relations. Monterey, CA, Brooks/Cole: 33-47.

Val, Andriana/Vinogradova, Polina (2010): What is the Identity of a Heritage Language Speaker? http://www.cal.org/heritage/pdfs/briefs/what-is-the-identity-of-a-heritagelanguage-speaker.pdf, accessed November 19, 2010.

\section{Appendix}

\begin{tabular}{|l|l|l|}
\hline Nr. & Yoruba & Reconfigured Names \\
\hline 1 & Yemi & Yhemmy \\
\hline 2 & Bisi & Beesee \\
\hline 3 & Oyekemi & Hoyekhemie \\
\hline 4 & Lara & Larrah \\
\hline 5 & Dedoyin & Dedoyn \\
\hline 6 & Buki & Bouque \\
\hline 7 & Lola & El-OH-EL-AHE \\
\hline 8 & Kikelomo & Khikhelormoh \\
\hline 9 & Teni & Xn \\
\hline 10 & Folakemi & Phorlarchemmy \\
\hline 11 & Kemi & Chemmy \\
\hline 12 & Mayowa & Maryourwah \\
\hline 13 & Abike & Harbeykhe \\
\hline 14 & Adeyemi & Hardeyyemmy \\
\hline 15 & Tosin & Tosyn \\
\hline 16 & Tolulope & Tholulorpe \\
\hline 17 & Bola & Burlar \\
\hline 18 & Dayo & Dayour \\
\hline 19 & Femi & Phemmy \\
\hline & & \\
\hline & & \\
\hline
\end{tabular}




\begin{tabular}{|c|c|c|}
\hline 20 & Fisayo & Phesayor \\
\hline 21 & Osho & Ochor \\
\hline 22 & Fola & 4 lar \\
\hline 23 & Okesola & Hokeychollar \\
\hline 24 & Olamide & Horlarmmydeh \\
\hline 25 & Olusola & Holuchollar \\
\hline 26 & Remi & Rhemmy \\
\hline 27 & Adeola & Hardeyholar \\
\hline 28 & Akintola & Harkintorlar \\
\hline 29 & Rolake & Rhorlarche \\
\hline 30 & Busola & Bhusawllar \\
\hline 31 & Omotayo & Hurmoretahyour \\
\hline 32 & Ayodeji & Haryoudehji \\
\hline 33 & Eyitope & Ehytorpeh \\
\hline 34 & Okuntade & Hokunterdey \\
\hline 35 & Abimbola & Harbeamborlah \\
\hline 36 & Fadekemi & Phadechemmy \\
\hline 37 & Temitope & Themytorpeh \\
\hline 38 & Aderounmu & Harderohunmu \\
\hline 39 & Funmi & Phunmie \\
\hline 40 & Аyo & Haryour \\
\hline 41 & Tola & Tollar \\
\hline 42 & Kike & Kheake \\
\hline 43 & Olakemi & Horlarchemmy \\
\hline 44 & Laide & Lyday \\
\hline 45 & Ademitayo & Hardemitahyour \\
\hline 46 & Kunle & Khunley \\
\hline 47 & Tomide & Thormydeh \\
\hline 48 & Dedoyin & /deIdəojın/ \\
\hline 49 & Laide & /laider/ \\
\hline 50 & Ronke & Rhonche \\
\hline
\end{tabular}

